\title{
Managing Urological Disorders in Multiple Sclerosis Patients: A Review of Available and Emerging Therapies
}

\author{
Riccardo Bientinesi, Carlo Gandi, PierFrancesco Bassi \\ Department of Urology, Catholic University Medical School, Agostino Gemelli Hospital Foundation - IRCCS, Rome, Italy
}

Multiple sclerosis (MS) is a progressive neurological autoimmune disease with a diverse range of urological symptomatology, and most MS patients experience 1 or more moderate to severe urinary symptoms, as well as bladder and/or sexual disorders. Urologists play the director's role in evaluating and treating these patients. Therefore, identifying the proper evaluation tools and the most suitable therapeutic options for specific patients requires a thorough understanding of this disease process.

Keywords: Multiple sclerosis; Lower urinary tract symptoms; Urinary incontinence; Neurogenic detrusor overactivity

- Conflict of Interest: No potential conflict of interest relevant to this article was reported.

\section{INTRODUCTION}

Multiple sclerosis (MS), which is the most frequently occurring progressive neurological autoimmune disease in young people, can affect any part of the central nervous system (CNS). The lifetime prevalence of MS is roughly 250 per 100,000 people [1]. MS is commonly diagnosed in younger adults ( $20-40$ years) and affects females 3-4 times more often than males. Lower urinary tract dysfunction (LUTD) has been reported to occur in the first 18 years after disease onset in up to $90 \%$ of MS patients [2,3]. In the 2005 North American Research Committee on Multiple Sclerosis survey of almost 10,000 patients with MS, $65 \%$ of participants reported experiencing 1 or more moderate to severe urinary symptoms, as well as bladder and sexual disorders [4]. In MS patients, lower urinary tract symptoms (LUTS) occur on a spectrum of severity, ranging from urgency to urge urinary incontinence, potentially accompanied by incomplete bladder emptying and/or hesitancy. The severity of LUTS and their presentation may vary considerably among MS patients as a result of the multifocal and diffuse involvement of the CNS. Roughly 70\% of MS patients indicated that they experienced a moderate or severe impact on their quality of life as a result of LUTS [5]. Furthermore, LUTS also pose an elevated risk for upper urinary tract integrity [6]. In diagnostic evaluations of patients with MS, the most frequently observed urological findings are urgency, frequency, and neurogenic detrusor overactivity (NDO) (34\%-99\%) [7].

\section{OBJECTIVES}

This study was conducted to review and summarize data on urological disorders and treatment options in patients with MS.

\section{METHODS}

A literature review (PubMed, Web of Science, and Scopus) was conducted for articles on urological dysfunction in MS patients.

Corresponding author: Riccardo Bientinesi (iD https://orcid.org/0000-0003-0757-152X Department of Urology, Catholic University Medical School, Agostino Gemelli Hospital Foundation - IRCCS, L.go F. Vito, Rome, Italy

E-mail: riccardo.bientinesi@gmail.com

Submitted: November 21, 2019 / Accepted after revision: February 18, 2020

(c) (1) (7) This is an Open Access article distributed under the terms of the Crecommons.org/licenses/by-nc/4.0/) which permits unrestricted non-commercial use, distribution, and reproduction in any medium, provided the original work is properly cited. 


\section{UROLOGICAL DISORDERS IN MULTIPLE SCLEROSIS}

Bladder dysfunction is the most frequently encountered disturbance of the autonomic nervous system in MS, but it is often inadequately diagnosed and insufficiently treated. According to a systematic review of recent articles presenting the findings of urodynamic studies in MS patients (12 studies, 1,524 patients), $53 \%$ of MS patients had detrusor overactivity (DO), $43 \%$ had detrusor sphincter dyssynergia (DSD), and $12 \%$ had atonic bladder. Magnetic resonance imaging (MRI) studies of MS patients have suggested an association between MS lesions in the corticospinal tract with progressive lower urinary tract bother, hesitancy, and urgency or frequency [8]. Cervical lesions are often linked to the presence of DSD [9]. Furthermore, urinary incontinence and weak stream have shown associations with lesions in the cerebellum and pons [10]. Over the course of disease progression, it is necessary to reassess MS patients in order to adjust their therapies. In many patients, conservative and pharmacological therapies show diminishing effectiveness, which may be due to the cumulative impact of physiological, cognitive, and physical changes over the course of MS $[10,11]$. For this reason, it is important to regularly change treatment regimens of MS patients for urological safety and to promote their quality of life. If conservative and pharmacological treatments become ineffective, it is important for both physicians and patients to understand the benefits, risks, and outcomes of secondary and tertiary treatments for LUTS related to MS.

Sexual dysfunctions (SDs) are also widespread among MS patients; although their prevalence is frequently underestimated, they may have a remarkably strong effect on patients' quality of life. SDs have been reported to be present in 50\%-90\% of MS patients $[12,13]$.

\section{OVERACTIVE BLADDER AND URGENCY URINARY INCONTINENCE}

The most frequently reported symptoms in MS patients involve the storage phase, and DO is the most common urodynamic finding. Anticholinergics are the first-line treatment for storage symptoms; acting on the detrusor muscle, anticholinergics can relieve muscle spasms, reduce bladder pressure, and relieve LUTS during urine storage. In patients with slight disability and overactive bladder (OAB) symptoms, pelvic floor muscle training (PFMT) may be beneficial [5]. For PFMT to be effective, the neural pathways leading to the pelvic floor must be intact, and patients must be able to contract the pelvic floor muscles. PFMT is thought to strengthen the inhibition exerted on the detrusor by pelvic floor contraction [11]. Several authors have demonstrated beneficial impacts of PFMT on the course of the disease [14]. As mentioned above, antimuscarinic agents (level of evidence: 1A) constitute the first line of treatment for neurogenic LUTS [15]. However, most findings on the efficacy and adverse effects of antimuscarinics have been obtained from patients with idiopathic DO. Only a few studies have investigated NDO, and only poor-quality data exist on patients with MS. A recent study evaluated the efficacy of $10 \mathrm{mg} /$ day of solifenacin compared with $50 \mathrm{mg} /$ day of mirabegron for treating DO in patients with MS. In total, 60 patients diagnosed with MS and NDO were evaluated. Patients were divided in 4 groups. In group A $(n=15)$ patients continued to receive solifenacin (10 $\mathrm{mg} /$ day); in group $B(\mathrm{n}=15)$ patients received mirabegron (50 $\mathrm{mg} /$ day); in group $\mathrm{C}(\mathrm{n}=15)$ patients received desmopressin $(120 \mu \mathrm{g} /$ day $)$, and in group $\mathrm{D}(\mathrm{n}=15)$ patients received mirabegron $(50 \mathrm{mg} /$ day $)$ and desmopressin $(120 \mu \mathrm{g} /$ day $)$. All patients were assessed using a 3-day bladder diary at the beginning and end of treatment. The results showed that all patients in groups $\mathrm{A}, \mathrm{B}$, and $\mathrm{C}$ did not demonstrate statistically significant changes at the end of the treatment period in their 3-day bladder diary and in the presence of urinary tract infections. In group $\mathrm{D}$, a statistically significant improvement was noted in the mean change from baseline to end of treatment in micturition episodes, urgency episodes, and the mean number of episodes of urinary incontinence ( $1.0 \pm 0.2$ episodes per 24 hours). The study demonstrated that treatment with mirabegron and desmopressin was both effective and safe in patients with NDO and MS [16].

Mirabegron alone $(50 \mathrm{mg}$ ) has been also demonstrated to improve both patient-reported outcomes and urodynamic variables in NDO, without relevant side effects [17]. A recent metaanalysis [18] showed the promise of cannabinoids as a safe and effective treatment modality for neurogenic LUTD in MS patients, as cannabinoids led to a meaningful reduction in the number of incontinence episodes in all 3 studies that were included in the meta-analysis. In addition, a recent observational study used clinical tools and instrumental analyses to evaluate the effects of a tetrahydrocannabinol-cannabidiol (THC/CBD) oromucosal spray on resistant OAB in MS patients [19]. The THC/CBD spray was successful in reducing OAB symptoms $(\mathrm{P}=0.001)$, suggesting that it might be effective for improving 
OAB symptoms in patients with MS, with beneficial effects on DO. However, the evidence base remains highly inadequate, and more high-quality, well-designed studies with suitable sample sizes and adequate power must be conducted to reach definitive conclusions.

As second- and third-line therapeutic strategies, catheterization, botulinum toxin (BTX) injections, and reconstructive surgery may also contribute to improvements in quality of life and safety for patients with MS. As more data on efficacy and safety are gathered, new emerging device-assisted modalities (e.g., neuromodulation) may play an increasingly salient role. Neuromodulation is a secondary or tertiary therapeutic strategy that can be used to treat refractory urinary incontinence and urinary retention. Although neuromodulation is best studied in individuals without neurological disorders, researchers are increasingly interested in the outcomes that might be achieved by using neuromodulation in MS patients to treat urinary symptoms. Peripheral tibial nerve stimulation (PTNS) is a minimally invasive technique that consists of electrically stimulating the posterior tibial nerve - a mixed sensory-motor nerve - through a small-gauge needle inserted close to the medial malleolus. Stimulation of this nerve potentiates the afferent branches of somatic nerves that pass through the L4-S3 spinal roots. Theoretically, stimulation of this pathway inhibits the central reflex pathways that cause uninhibited detrusor contractions. Some prospective studies have investigated PTNS in MS patients with LUTS refractory to medical therapy [20], with outcomes including a decreased frequency of daytime voiding (from 9 to 6 voids) and nocturia (from 3 to 1 void). Another study of $21 \mathrm{MS}$ patients showed that extending maintenance PTNS treatments led to a reduction in daily voiding by 5.4 voids; furthermore, urinary incontinence decreased by 3.4 episodes daily, urgency episodes were reduced by 7.4 daily, nocturia decreased by 2.6 voids per night, and voided volume improved by $72.1 \mathrm{~mL}$ on average [21]. In a recent retrospective case series on the use of PTNS to treat neurogenic and idiopathic OAB [22], significant improvements were found after 12 weeks for quality of life $(\mathrm{P}=0.004), \mathrm{OAB}$ symptoms $(\mathrm{P}=0.01)$, incontinence severity according to a bladder diary $(\mathrm{P}=0.007)$, the number of episodes of incontinence according to a bladder diary, and 24hour frequency according to a bladder diary $(\mathrm{P}=0.002)$. That study indicated that PTNS could be a promising potential alternative for patients with neurological disorders, especially MS, who report OAB symptoms, and in whom first-line treatments are either ineffective or cannot be tolerated. Nonetheless, there is still a need for suitably designed studies to investigate the efficacy and safety of PTNS. Sacral nerve stimulation (SNS; InterStim, Medtronic, Fridley, MN, USA) is indicated for refractory $\mathrm{OAB}$, nonobstructive urinary retention, and fecal incontinence. Similarly to PTNS, quite limited data are available on the outcomes of SNS in patients with progressive neurological diseases, such as MS. However, significant improvements have been shown to result from SNS in well-selected MS patients in studies with a limited sample size [23]. Concerns about the frequent need for whole-body MRI scans in MS patients have contributed to the limited adoption of neuromodulation devices as a treatment for MS. For this reason, and given the unknown long-term efficacy of neuromodulation, limiting SNS to MS patients with a clinically isolated syndrome or stable relapsing and remitting disease may be prudent.

\section{DETRUSOR SPHINCTER DYSSYNERGIA}

Voiding dysfunction (VD) is a common consequence of MS that may be debilitating. More severe MS is associated with a higher prevalence and severity of VD, but voiding LUTS can occur even in patients with the mildest forms of the disease, as shown by the fact that voiding LUTS have been reported in $30 \%$ of MS patients [2,3]. MS can cause a broad range of urinary symptoms and urological complications because the voiding phase is regulated by each component of the CNS. The effects of MS on voiding can be categorized based on the function of the bladder and the urethral sphincter during urine storage and emptying. Urodynamic parameters are currently the most effective method for identifying the type of VD in patients with MS (DSD or acontractile bladder). DSD is defined as the loss of coordination between the detrusor and external sphincter in patients with neurological pathology. According to a systematic review of recent articles presenting the findings of urodynamic studies in MS patients (12 studies, 1,524 patients), 53\% of MS patients had DO, $43 \%$ had DSD, and $12 \%$ had atonic bladder [2]. Despite the lack of a standard definition of MS-related urinary retention, it has been proposed that a postvoiding residual volume greater than $300 \mathrm{~mL}$ should be used as a threshold based on a review of the literature. Patients with DSD have an elevated risk for upper tract impairment, autonomic dysreflexia, and recurrent urinary tract infections unless they receive appropriate follow-up and treatment. The basis of treatment should be risk stratification for morbidity from retention and the symptoms caused by retention. Regarding risk stratification, 
in 1981 Blaivas et al. [24] proposed a classification of DSD into 3 types, where type 1 is characterized by a crescendo increase in electromyographic (EMG) activity, type 2 by clonic sphincter contractions throughout the detrusor contraction, and type 3 by a sustained increase in activity. Approximately 20 years later, Weld et al. [25] classified DSD as continuous or intermittent on the basis of EMG patterns. Despite being conceptually intriguing, these systems are not generally used in everyday clinical practice because they have failed to demonstrate ongoing prognostic value in clinical settings. For this reason, in routine clinical practice, risk stratification is based on the intensity and frequency of LUTS due to MS. Before initiating any therapy, clinicians should first identify the goals of treatment. In general, a first step is to determine whether the primary treatment goal is to improve quality of life, safety, or both. Once this is established, target outcomes should reflect the goals of treatment, and patients should receive frequent follow-up clinical evaluations to assess whether the treatment is effective. Repeated urodynamic studies should be performed to determine the stability of postintervention improvements in DSD. The guidelines of the European Association of Urology (EAU) [26] suggest that the primary aims when treating neurogenic disorders are to protect the upper urinary tract, to improve urinary continence, to restore (at least partially) lower urinary tract function, and to improve the patient's quality of life. Further considerations include potential complications, the technical complexity of the intervention, its cost-effectiveness, and the patient's disability status [27].

Alpha-blockers are considered to be the first-line pharmacological treatment for DSD (level of evidence: 1B), with the aim of reducing bladder outlet resistance. The efficacy of tamsulosin was evaluated by Abrams et al. [28] in 263 patients with neurogenic LUTD secondary to supra-sacral spinal cord lesions. A 4-week trial (with a placebo control group) yielded no statistically significant reduction in maximal urethral pressure, the primary endpoint of the study. Nonetheless, an increase in mean voided volume (assessed through a bladder diary) and improvements in quality of life (evaluated using the International Prostate Symptom Score [IPSS]) and the severity of symptoms of autonomic dysreflexia were reported in a 1-year, open-label extension study. Data on the use of alpha-blockers in MS patients remain poor, particularly in women. Nonetheless, several European consensus statements recommend this class of drugs for voiding symptoms, especially in men in whom benign prostatic obstruction is expected to contribute to the symptoms [28-31]. The efficacy of alpha-blockers in treating DSD was also tested by Chancellor et al. [32]; in that study, $5 \mathrm{mg}$ of terazosin was given to 15 normotensive DSD patients with spinal cord injuries, and urodynamic findings showed no reduction in voiding pressure. Contrastingly, Stankovich et al. [33] used $0.4 \mathrm{mg}$ of tamsulosin in MS patients with DSD, and reported significant improvements in postvoid residual measurements and the mean volume of voided urine. Since data supporting efficacy are still lacking, alpha-blockers are still not a recommended therapy for symptomatic DSD.

Similarly, baclofen has also been tested with the objective of reducing DSD severity in patients suffering from neurogenic bladder. Despite the value of oral baclofen in treating skeletal muscle spasticity, its permeability across the blood-brain barrier is low, which limits its potential usefulness for the treatment of DSD. Nonetheless, intrathecal baclofen delivery may directly inhibit interneurons in Onuf's nucleus, thereby inhibiting the external sphincter [34]. Several small trials and case reports have provided support for the efficacy of baclofen in mitigating DSD [35,36], but no randomized trials have been reported and its long-term benefits remain poorly understood.

Intrasphincteric injections of BTX are an option for treating DSD, with the dosage depending on the specific preparation. BTX-A can be injected transurethrally, directly into the external sphincter, or through a transperineal approach under ultrasound guidance. Injections are usually made into the sphincter at 2-3 points between the 9-oclock and 3-oclock positions. Despite a lack of standardization of the injection technique into the external sphincter, most studies have suggested a total BTXA dose of $100 \mathrm{U}$. If the procedure is performed via cystoscopy, the injection must be at least $1 \mathrm{~cm}$ deep in the submucosa in order to treat the sphincter muscle and to avoid injecting BTXA into the submucosal space. After treatment, DSD resolves for only a few months, making repeated injections necessary. This treatment has high efficacy and few adverse effects [37,38], for which reason it received a grade $\mathrm{A}$ recommendation in the EAU guidelines.

Intermittent catheterization (IC) is a primary treatment for managing DSD-related symptoms. In order to preserve upper urinary tract integrity, when treating progressive hydronephrosis due to low bladder compliance or chronic urinary tract infections, it is necessary for the patient to empty the bladder only by catheterization, and to avoid making attempts to void until the situation stabilizes. The schedule of IC should be daily, with a sufficient frequency to reduce the standing volume. Patients 
should be instructed to pass the catheter to the level of the sphincter, and then to wait for spasms to reduce before continuing to pass the catheter. During follow-up, the effectiveness of the treatment in resolving hydronephrosis should be evaluated by renal ultrasound exams, which also help to avoid complications. In cases where DSD has caused urinary retention, and thus LUTS, it is possible to perform IC postvoiding to completely empty the bladder. In patients suffering from overflow incontinence, especially at night, this strategy is a very good option for preserving quality of life. Screening urine cultures in asymptomatic patients performing IC is not recommended because of the risk of overtreating bacterial colonization. Finally, in patients in poor physical condition who cannot perform IC, indwelling catheters can be considered [39].

\section{SEXUAL DYSFUNCTIONS}

SDs occur frequently in patients with MS, but they are frequently underestimated, even though they may have a remarkably strong impact on quality of life. SDs have been reported to be present in 50\%-90\% of MS patients, depending on patients' clinical characteristics and the length of follow-up [12,13]. In MS patients, SDs comprise diverse conditions, associated with anatomical, physiological, biological, medical, and psychological factors [40]. They are more common in MS patients than in those with other neurological diseases, and are almost 5 times more frequently encountered in MS patients than in the general population [41]. Erectile dysfunction (ED) is the most common sexuality-related complaint in men with MS. A recent observational, cross-sectional study of a cohort of male MS patients [42] evaluated the prevalence of ED and its relationships with urodynamic findings, LUTS, depression, and neurological disabilities, and showed a high prevalence of $\mathrm{ED}$ (74.2\%). A significant relationship between depression and SDs was also found (57.4\%); in MS patients, depression was the most common psychiatric disorder and had a higher prevalence than other chronic diseases [43]. In a recent prospective, single-blind study, men with MS were administered $5 \mathrm{mg}$ of tadalafil daily using a notreatment group as a control. The results showed improved International Index of Erectile Function $(\mathrm{P}<0.001)$, IPSS $(\mathrm{P}<$ $0.001)$, and $\mathrm{OAB}$ questionnaire $(\mathrm{P}<0.001)$ scores in the treatment group. Furthermore, an increase in maximal flow rate $(\mathrm{P}<0.01)$ and the testosterone-to-estradiol ratio [44] $(\mathrm{P}<0.01)$ were found, accompanied by reduced postvoid residual volume $(\mathrm{P}<0.001)$ and no changes in the H-reflex [44]. In a cross-sec- tional study, 41 men affected by MS were evaluated. Orgasmic dysfunction was graded as severe in 14 patients $(35.9 \%)$ and as moderate in 5 (12.8\%), while only 8 patients $(20.5 \%)$ reported normal orgasmic function. The reduction in sexual desire was categorized as severe in 2 patients (5.1\%) and moderate in 11 patients (28.2\%), and only 12 patients (30.8\%) reported normal sexual desire. Twenty-three patients (59\%) stated that they experienced moderate or severe dissatisfaction during sexual intercourse $(23.1 \%$ and $35.9 \%$, respectively), while 3 patients (7.7\%) described themselves as satisfied. In terms of their overall satisfaction with sexual life, 11 patients (28.2\%) considered themselves to be severely dissatisfied, 10 (25.6\%) reported being moderately dissatisfied, and only 6 patients (15.4\%) were satisfied [45]. A recent prospective, monocentric, noninterventional study investigated the prevalence of ejaculation disorders in MS patients, and showed that dysejaculation was present in $64 \%$ of MS patients, including a decrease in the volume of the ejaculation, the strength of ejaculation, and delay in ejaculation [46].

Phosphodiesterase-5 inhibitors (PDE5i) are deemed to be the first line of treatment for patients with neurological disorders suffering from ED [47]. To date, only 3 studies investigating the effects of PDE5i in patients with MS have been published; 2 of these were double-blind, placebo-controlled, randomized trials of sildenafil $[48,49]$, and the other was a case series on tadalafil [50]. These studies reported significantly improved erectile function and ability to engage in satisfactory sexual activity for the majority of the patients (73\%-95\%). It has been also seen that the restoration of erectile function seems to improve orgasmic sensations.

Intracavernous injection (ICI) of papaverine has emerged as a major step forward in managing ED in patients with neurological conditions. Excellent results of this treatment - with success rates as high as $92 \%$ - have been reported for patients with MS [51]. However, to achieve these results, patients either received a considerable dosage of papaverine (up to $80 \mathrm{mg}$ ) or also received phentolamine, placing these patients at an elevated risk of priapism. For these reasons, papaverine was withdrawn from the market, making prostaglandin E1 (alprostadil) the only vasoactive drug that can be administered through ICI. Alprostadil has shown high levels of efficacy, both in men with spinal cord injuries and in those with MS [52,53]. Intraurethral alprostadil (Muse) and oral apomorphine have rarely been used in MS patients, as they showed disappointing results in men with spinal cord injuries. In some patients - mainly older men in long-term, stable relationships - vacuum constriction devic- 
es may be an alternative [54]. Surgical implantation of a penile prosthesis is only considered in rare cases.

For ejaculatory dysfunction, penile vibratory stimulation is considered to be the first-line treatment in men with spinal cord injuries who do not ejaculate during sexual intercourse. This method has been widely used, with a success rate of $52 \%$ in this population [55]. Oral midodrine can enhance this result [56]. Only limited data exist on penile vibratory stimulation in patients with MS, but some data show that it can be effective. Oral midodrine restored ejaculation in some patients with MS, without requiring vibratory stimulation [57]. Electroejaculation [58] and surgical sperm retrieval [59] constitute other effective options.

Hypoactive sexual desire has been reported in $31.4 \%-74.4 \%$ of women with MS [60], decreased lubrication in $35.7 \%-48.4 \%$ [61], and orgasmic dysfunction in 37\%-44.9\% [62]. Dyspareunia has been reported in $31 \%-72 \%$ of women with MS [63], and other complaints relating to the consequences (indirect or direct) of MS for sexual function have also been described. Due to the complexity of sexual function in women, treatment of both the physical and psychosocial aspects of SD has been frequently recommended for these patients [64]. Studies of sildenafil have shown that it is safe for treating SD in women with MS [65]. Dasgupta et al. [66] reported that sildenafil yielded significant improvements in lubrication, but not in the ability to reach orgasm or quality of life. In combination with PDE5i, it is possible that alpha-blockers may further facilitate vascular smooth muscle relaxation, but their real effects have yet to be demonstrated [67]. Estrogen replacement therapy and/or the use of lubricants can mitigate symptoms related to dyspareunia, vaginal dryness, and burning. It has been reported that topical estrogen improved clitoral sensitivity and reduced pain during intercourse [67]. Since changes in interpersonal relationships, depression, and reduced self-image may damage sexual function as much as disruptions to nerve circuits - or even more so - therapeutic interventions for treating SDs should include sexual and relationship therapy, behavioral approaches, psychotherapy, and general counseling [68].

Natalizumab has been approved as a disease-modifying therapy used to treat relapsing forms of MS. Patients using natalizumab have also shown improvements in health-related quality of life parameters, including cognition and fatigue [69]. In 2018, Robertson et al. [70] performed a single-center, openlabel, single-arm, 24-week study that evaluated perceived changes in SDs in MS patients who received natalizumab treat- ment. In patients on natalizumab therapy, the primary subscale of the Multiple Sclerosis Intimacy and Sexuality Questionnaire-19 showed a statistically significant decrease over time in the mean score for SDs $(-0.6976, \mathrm{P}=0.02)$. However, the study had multiple limitations - including a relatively small sample size and the lack of a placebo group or active comparator arm - that prevented definitive conclusions about the effects of natalizumab on SD from being drawn.

In conclusion, we can assert that MS is a complex, progressive disease with primary, secondary, and tertiary consequences for sexual function. Early professional support should be offered to women and men with MS to encourage them to express their sexual needs and verbalize their sexual concerns; furthermore, they should receive suitable information, counseling, and treatment in order to overcome their difficulties. Ongoing assessments should be conducted, and treatments should be regularly adjusted as appropriate given patients' neurological condition and sexual deficits.

\section{CONCLUSIONS}

MS is a neurological autoimmune disease with a diverse variety of urological presentations. Urologists play the director's role in evaluating and treating these patients. To choose the most suitable evaluation tools and the most proper management options for specific patients, it is vital to have a thorough knowledge of the disease process. In MS patients, LUTS should be evaluated and managed with the goal of identifying those who are at an elevated risk for upper urinary tract deterioration and/or impaired quality of life. Anticholinergics - with or without IC are the first-line treatment for symptoms of OAB. If conservative therapy does not succeed in reducing the risk of upper urinary tract deterioration or fails to improve patients' symptoms because of limited efficacy or adverse events, second-line therapies are needed. The introduction of intradetrusor injections of BTX-A has radically changed the available options for treating refractory cases. However, further research in patients with MS is required to determine more conclusively the real-world effects of sacral neuromodulation, BTX, and anticholinergic agents. Moreover, both male and female MS patients experience diminished sexual function, which appears to be associated with more severe disability, pain, and accompanying depression. For this reason, MS patients should also receive evaluations for sexual function and disability during follow-up. 


\section{AUTHOR CONTRIBUTION STATEMENT}

\author{
- Conceptualization: $R B$ \\ - Formal Analysis: $R B, C G$ \\ - Investigation: $R B, C G$ \\ - Methodology: $R B, P F B$ \\ - Project Administration: $R B$ \\ -Writing - Original Draft: $R B, C G$ \\ -Writing - Review \& Editing: $R B$
}

\section{REFERENCES}

1. Compston A, Coles A. Multiple sclerosis. Lancet 2002;359:1221-31.

2. de Sèze M, Ruffion A, Denys P, Joseph PA, Perrouin-Verbe B; GENULF. The neurogenic bladder in multiple sclerosis: review of the literature and proposal of management guidelines. Mult Scler 2007;13:915-28.

3. Phé V, Chartier-Kastler E, Panicker JN. Management of neurogenic bladder in patients with multiple sclerosis. Nat Rev Urol 2016; 13:275-88.

4. Mahajan ST, Patel PB, Marrie RA. Under treatment of overactive bladder symptoms in patients with multiple sclerosis: an ancillary analysis of the NARCOMS Patient Registry. J Urol 2010;183:14327.

5. Fowler CJ, Panicker JN, Drake M, Harris C, Harrison SC, Kirby M, et al. A UK consensus on the management of the bladder in multiple sclerosis. J Neurol Neurosurg Psychiatry 2009;80:470-7.

6. Lemack GE, Hawker K, Frohman E. Incidence of upper tract abnormalities in patients with neurovesical dysfunction secondary to multiple sclerosis: analysis of risk factors at initial urologic evaluation. Urology 2005;65:854-7.

7. Wein AJ, Dmochowski RR. Neuromuscular dysfunction of the lower urinary tract. In: Wein AJ, Kavoussi LR, Novick AC, Partin AW, Peters CA, editors. Campbell-Walsh Urology. 11th ed. St. Louis (MO): Elsevier Mosby; 2016. p. 1761-95.

8. Fowler CJ, Griffiths D, de Groat WC. The neural control of micturition. Nat Rev Neurosci 2008;9:453-66.

9. Araki I, Matsui M, Ozawa K, Takeda M, Kuno S. Relationship of bladder dysfunction to lesion site in multiple sclerosis. J Urol 2003; 169:1384-7.

10. Weissbart SJ, Pechersky D, Malykhina A, Bavaria T, Parrillo L, Arya LA, et al. The impact of pontine disease on lower urinary tract symptoms in patients with multiple sclerosis. Neurourol Urodyn 2017;36:453-6.

11. Amaro JL, Gameiro MO, Padovani CR. Effect of intravaginal elec- trical stimulation on pelvic floor muscle strength. Int Urogynecol J Pelvic Floor Dysfunct 2005;16:355-8.

12. Schmidt EZ, Hofmann P, Niederwieser G, Kapfhammer HP, Bonelli RM. Sexuality in multiple sclerosis. J Neural Transm (Vienna) 2005;112:1201-11.

13. Tepavcevic DK, Kostic J, Basuroski ID, Stojsavljevic N, Pekmezovic T, Drulovic J. The impact of sexual dysfunction on the quality of life measured by MSQoL-54 in patients with multiple sclerosis. Mult Scler 2008;14:1131-6.

14. McClurg D, Ashe RG, Marshall K, Lowe-Strong AS. Comparison of pelvic floor muscle training, electromyography biofeedback, and neuromuscular electrical stimulation for bladder dysfunction in people with multiple sclerosis: a randomized pilot study. Neurourol Urodyn 2006;25:337-48.

15. Stöhrer M, Blok B, Castro-Diaz D, Chartier-Kastler E, Del Popolo $\mathrm{G}$, Kramer G, et al. EAU guidelines on neurogenic lower urinary tract dysfunction. Eur Urol 2009;56:81-8.

16. Zachariou A, Filiponi M, Baltogiannis D, Giannakis J, Dimitriadis F, Tsounapi $\mathrm{P}$, et al. Effective treatment of neurogenic detrusor overactivity in multiple sclerosis patients using desmopressin and mirabegron. Can J Urol 2017;24:9107-13.

17. Krhut J, Borovička V, Bílková K, Sýkora R, Míka D, Mokriš J, et al. Efficacy and safety of mirabegron for the treatment of neurogenic detrusor overactivity-Prospective, randomized, double-blind, placebo-controlled study. Neurourol Urodyn 2018;37:2226-33.

18. Abo Youssef N, Schneider MP, Mordasini L, Ineichen BV, Bachmann $\mathrm{LM}$, Chartier-Kastler E, et al. Cannabinoids for treating neurogenic lower urinary tract dysfunction in patients with multiple sclerosis: a systematic review and meta-analysis. BJU Int 2017;119:515-21.

19. Maniscalco GT, Aponte R, Bruzzese D, Guarcello G, Manzo V, Napolitano $\mathrm{M}$, et al. THC/CBD oromucosal spray in patients with multiple sclerosis overactive bladder: a pilot prospective study. Neurol Sci 2018;39:97-102.

20. Gobbi C, Digesu GA, Khullar V, El Neil S, Caccia G, Zecca C. Percutaneous posterior tibial nerve stimulation as an effective treatment of refractory lower urinary tract symptoms in patients with multiple sclerosis: preliminary data from a multicentre, prospective, open label trial. Mult Scler 2011;17:1514-9.

21. Canbaz Kabay S, Kabay S, Mestan E, Cetiner M, Ayas S, Sevim M, et al. Long term sustained therapeutic effects of percutaneous posterior tibial nerve stimulation treatment of neurogenic overactive bladder in multiple sclerosis patients: 12-months results. Neurourol Urodyn 2017;36:104-10.

22. Tudor KI, Seth JH, Liechti MD, Ochulor J, Gonzales G, Haslam C, et al. Outcomes following percutaneous tibial nerve stimulation 
(PTNS) treatment for neurogenic and idiopathic overactive bladder. Clin Auton Res 2020;30:61-7.

23. Engeler DS, Meyer D, Abt D, Müller S, Schmid HP. Sacral neuromodulation for the treatment of neurogenic lower urinary tract dysfunction caused by multiple sclerosis: a single-centre prospective series. BMC Urol 2015;15:105.

24. Blaivas JG, Sinha HP, Zayed AA, Labib KB. Detrusor-external sphincter dyssynergia: a detailed electromyographic study. J Urol 1981;125:545-8.

25. Weld KJ, Graney MJ, Dmochowski RR. Clinical significance of detrusor sphincter dyssynergia type in patients with post-traumatic spinal cord injury. Urology 2000;56:565-8.

26. Groen J, Pannek J, Castro Diaz D, Del Popolo G, Gross T, Hamid R, et al. Summary of European Association of Urology (EAU) Guidelines on Neuro-Urology. Eur Urol 2016;69:324-33.

27. Castro-Diaz D, Barrett D, Grise P, Perkash I, St Hrer M, Stone A, et al. Surgery for the neuropathic patient. In: Abrams P, Khoury S, Wein A, editors. In: Incontinence. 2nd ed. Plymouth (UK): Health Publication; 2002. p. 865-91.

28. Abrams P, Amarenco G, Bakke A, Buczyński A, Castro-Diaz D, Harrison S, et al. Tamsulosin: efficacy and safety in patients with neurogenic lower urinary tract dysfunction due to suprasacral spinal cord injury. J Urol 2003;170(4 Pt 1):1242-51.

29. Amarenco G, Chartier-Kastler E, Denys P, Jean JL, de Sèze M, Lubetzski C. First-line urological evaluation in multiple sclerosis: validation of a specific decision-making algorithm. Mult Scler 2013;19:1931-7.

30. De Ridder D, Van Der Aa F, Debruyne J, D'hooghe MB, Dubois B, Guillaume D, et al. Consensus guidelines on the neurologist's role in the management of neurogenic lower urinary tract dysfunction in multiple sclerosis. Clin Neurol Neurosurg 2013;115:2033-40.

31. Ghezzi A, Carone R, Del Popolo G, Amato MP, Bertolotto A, Comola $\mathrm{M}$, et al. Recommendations for the management of urinary disorders in multiple sclerosis: a consensus of the Italian Multiple Sclerosis Study Group. Neurol Sci 2011;32:1223-31.

32. Chancellor MB, Erhard MJ, Rivas DA. Clinical effect of alpha-1 antagonism by terazosin on external and internal urinary sphincter function. J Am Paraplegia Soc 1993;16:207-14.

33. Stankovich EIu, Borisov VV, Demina TL. Tamsulosin in the treatment of detrusor-sphincter dyssynergia of the urinary bladder in patients with multiple sclerosis. Urologiia 2004;(4):48-51.

34. Blok BF, Holstege G. Ultrastructural evidence for a direct pathway from the pontine micturition center to the parasympathetic preganglionic motoneurons of the bladder of the cat. Neurosci Lett 1997;222:195-8.
35. Meythaler JM, Steers WD, Tuel SM, Cross LL, Haworth CS. Continuous intrathecal baclofen in spinal cord spasticity. A prospective study. Am J Phys Med Rehabil 1992;71:321-7.

36. Bushman W, Steers WD, Meythaler JM. Voiding dysfunction in patients with spastic paraplegia: urodynamic evaluation and response to continuous intrathecal baclofen. Neurourol Urodyn 1993;12:163-70.

37. Dykstra DD, Sidi AA. Treatment of detrusor-sphincter dyssynergia with botulinum A toxin: a double-blind study. Arch Phys Med Rehabil 1990;71:24-6.

38. Schurch B, Hauri D, Rodic B, Curt A, Meyer M, Rossier AB. Botulinum-A toxin as a treatment of detrusor-sphincter dyssynergia: a prospective study in 24 spinal cord injury patients. J Urol 1996;155:1023-9.

39. Mahajan ST, Frasure HE, Marrie RA. The prevalence of urinary catheterization in women and men with multiple sclerosis. J Spinal Cord Med 2013;36:632-7.

40. Lundberg PO. Sexual dysfunction in female patients with multiple sclerosis. Int Rehabil Med 1981;3:32-4.

41. Zorzon M, Zivadinov R, Bosco A, Bragadin LM, Moretti R, Bonfigli $\mathrm{L}$, et al. Sexual dysfunction in multiple sclerosis: a case-control study. I. Frequency and comparison of groups. Mult Scler 1999;5:418-27.

42. Balsamo R, Arcaniolo D, Stizzo M, Illiano E, Autorino R, Natale F, et al. Increased risk of erectile dysfunction in men with multiple sclerosis: an Italian cross-sectional study. Cent European J Urol 2017;70:289-95.

43. Feinstein A, Feinstein K. Depression associated with multiple sclerosis. Looking beyond diagnosis to symptom expression. J Affect Disord 2001;66:193-8.

44. Francomano D, Ilacqua A, Cortese A, Tartaglia G, Lenzi A, Inghilleri $\mathrm{M}$, et al. Effects of daily tadalafil on lower urinary tract symptoms in young men with multiple sclerosis and erectile dysfunction: a pilot study. J Endocrinol Invest 2017;40:275-9.

45. Tomé ALF, Miranda EP, de Bessa Júnior J, Bezerra CA, Pompeo ACL, Glina S, et al. Lower urinary tract symptoms and sexual dysfunction in men with multiple sclerosis. Clinics (Sao Paulo) 2019;74:e713.

46. Blum C, Chesnel C, Hentzen C, Turmel N, Lacroix P, Manceau P, et al. Troubles de léjaculation et sclérose en plaques: étude prospective de 44 patients [Ejaculation disorders in multiple sclerosis: Prospective study of 44 patients]. Prog Urol 2019;29:385-90.

47. Lombardi G, Nelli F, Celso M, Mencarini M, Del Popolo G. Treating erectile dysfunction and central neurological diseases with oral phosphodiesterase type 5 inhibitors. Review of the literature. J Sex Med 2012;9:970-85.

48. Fowler CJ, Miller JR, Sharief MK, Hussain IF, Stecher VJ, Sweeney M. A double blind, randomised study of sildenafil citrate for erec- 
tile dysfunction in men with multiple sclerosis. J Neurol Neurosurg Psychiatry 2005;76:700-5.

49. Safarinejad MR. Evaluation of the safety and efficacy of sildenafil citrate for erectile dysfunction in men with multiple sclerosis: a doubleblind, placebo controlled, randomized study. J Urol 2009;181:252-8.

50. Lombardi G, Macchiarella A, Del Popolo G. Efficacy and safety of tadalafil for erectile dysfunction in patients with multiple sclerosis. J Sex Med 2010;7:2192-200.

51. Kirkeby HJ, Petersen T, Poulsen EU. Pharmacologically induced erection in patients with multiple sclerosis. Scand J Urol Nephrol 1988;22:241-4.

52. Lebib Ben Achour S, Laffont I, Boyer F, Boiteau F, Dizien O. Utilisation des injections intracaverneuses dans les dysfonctionnements érectiles du blessé médullaire: à propos d'une expérience sur 36 patients [Intracavernous injections in the treatment of erectile dysfunction in spinal cord injured patients: experience with $36 \mathrm{pa}-$ tients]. Ann Readapt Med Phys 2001;44:35-40.

53. Hirsch IH, Smith RL, Chancellor MB, Bagley DH, Carsello J, Staas WE Jr. Use of intracavernous injection of prostaglandin E1 for neuropathic erectile dysfunction. Paraplegia 1994;32:661-4.

54. Heller L, Keren O, Aloni R, Davidoff G. An open trial of vacuum penile tumescence: constriction therapy for neurological impotence. Paraplegia 1992;30:550-3.

55. Chéhensse C, Bahrami S, Denys P, Clément P, Bernabé J, Giuliano F. The spinal control of ejaculation revisited: a systematic review and meta-analysis of anejaculation in spinal cord injured patients. Hum Reprod Update 2013;19:507-26.

56. Soler JM, Previnaire JG, Plante P, Denys P, Chartier-Kastler E. Midodrine improves ejaculation in spinal cord injured men. J Urol 2007;178:2082-6.

57. Safarinejad MR. Midodrine for the treatment of organic anejaculation but not spinal cord injury: a prospective randomized placebo-controlled double-blind clinical study. Int J Impot Res 2009;21:213-20.

58. Fan LC, Liu JH. Penile vibratory stimulation and electroejaculation in the treatment of ejaculatory dysfunction. Zhonghua Nan Ke Xue
2005;11:219-22.

59. Cavalla P, Rovei V, Masera S, Vercellino M, Massobrio M, Mutani $\mathrm{R}$, et al. Fertility in patients with multiple sclerosis: current knowledge and future perspectives. Neurol Sci 2006;27:231-9.

60. Bronner G, Elran E, Golomb J, Korczyn AD. Female sexuality in multiple sclerosis: the multidimensional nature of the problem and the intervention. Acta Neurol Scand 2010;121:289-301.

61. Hulter BM, Lundberg PO. Sexual function in women with advanced multiple sclerosis. J Neurol Neurosurg Psychiatry 1995;59:83-6.

62. Lew-Starowicz M, Rola R. Prevalence of sexual dysfunctions among women with multiple sclerosis. Sex Disabil 2013;31:141-53.

63. Sacco E, Sebastianelli A, Batocchi A, Marti A, Pinto F, Totaro A, et al. Sexual dysfunctions in patients affected by multiple sclerosis: evaluation in a contemporary cohort from a referral center. Eur Urol Suppl 2011;10:160. https://doi.org/10.1016/S1569-9056(11)60462-4.

64. Merghati-Khoei E, Qaderi K, Amini L, Korte JE. Sexual problems among women with multiple sclerosis. J Neurol Sci 2013;331:81-5.

65. Dachille G, Ludovico GM, Pagliarulo G, Vestita G. Sexual dysfunctions in multiple sclerosis. Minerva Urol Nefrol 2008;60:77-9.

66. Dasgupta R, Wiseman OJ, Kanabar G, Fowler CJ, Mikol D. Efficacy of sildenafil in the treatment of female sexual dysfunction due to multiple sclerosis. J Urol 2004;171:1189-93; discussion 1193.

67. DasGupta R, Fowler CJ. Bladder, bowel and sexual dysfunction in multiple sclerosis: management strategies. Drugs 2003;63:153-66.

68. Calabrò RS, De Luca R, Conti-Nibali V, Reitano S, Leo A, Bramanti P. Sexual dysfunction in male patients with multiple sclerosis: a need for counseling! Int J Neurosci 2014;124:547-57.

69. Rudick RA, Miller D, Hass S, Hutchinson M, Calabresi PA, Confavreux $C$, et al. Health-related quality of life in multiple sclerosis: effects of natalizumab. Ann Neurol 2007;62:335-46.

70. Robertson D, Aungst A, Collier R, Vivar J, Moreo N, Casady L, et al. Patient perceived changes in sexual dysfunction after initiation of natalizumab for multiple sclerosis. Mult Scler J Exp Transl Clin 2018;4:2055217318781989. 